NBER WORKING PAPERS SERIES

EXCHANGE RATE FLEXIBILITY, VOLATILITY, AND THE PATTERNS

OF DOMESTIC AND FOREIGN DIRECT INVESTMENT

Joshua Aizenman

Working Paper No. 3953

\author{
NATIONAL BUREAU OF ECONOMIC RESEARCH \\ 1050 Massachusetts Avenue \\ Cambridge, MA 02138 \\ January 1992
}

This paper is part of NBER's research program in International Studies. Any opinions expressed are those of the author and not those of the National Bureau of Economic Research. 
NBER Working Paper \#3953

January 1992

\title{
EXCHANGE RATE FI.EXIBILITY, VOLATILITY, AND THE PATTERNS OF DOMESTIC AND FOREIGN DIRECT INVESTMENT
}

\begin{abstract}
The goal of this paper is to investigate the factors determining the impact of exchange rate regimes on the behavior of domestic investment and foreign direct investment (FDI), and the correlation between exchange rate volatility and investment. We assume that producers may diversify intemationally in order to increase the flexibility of production: being a multinational enables producers to reallocate employment and production towards the more efficient or the cheaper plant. We characterize the possible equilibria in a macro model that allows for the presence of a short-run Phillips curve, under a fixed and a flexible exchange rate regime. It is shown that a fixed exchange rate regime is more conducive to FDI relative to a flexible exchange rate, and this conclusion applies for both real and nominal shocks. The correlation between investment and exchange rate volatility under a flexible exchange rate is shown to depend on the nature of the shocks. If the dominant shocks are nominal, we will observe a negative correlation, whereas if the dominant shocks are real, we will observe a positive correlation between exchange rate volatility and the level of investment.
\end{abstract}

Joshua Aizenman Economics Department Dartmouth College Hanover, NH 03755 and NBER 


\section{Introduction and Summiry}

The purpose of this paper is to analyze the implications of exchange rate flexibility on the patterns of domestic and foreign direct investment (FDI). The inportance of this topic stems from several observations. The recent two decades have been characterized by the growing integration of capital markets, and the substantial increase in the importance of FDI flows. Figure 1 traces the evolution of the ratio of FDI flows relative to merchandise tracle for industrialized and the developing countries. I It reveals that from the mid seventies until 1981- 1982 the trend towards higher relative importance of FDI flows was common to both groups of nations. Following the debt crisis we observed a decline in that ratio for developing countries in the late eighties, while the upward trend continued for the industrialized nations. The recent experience of Mexico and Chile suggests that a resolution of the debt crisis will revitalize the upward trend in the relative importance of FDI for the developing countries. Throughout that period, we observed various types of exchange rate regimes. On balance, the European countries adopted policies whose goal was to minimize the fluctuations of their bilateral exchange rates. The United States, Japan, and Canada adhered to a flexible exchange rate system, which implies that each of them adapted a flexible exchange rate with regard to the European block. Most developing countries adopted a fixed exchange rate or a crawling peg.

These observations suggest that further attention should be given to the degree to which the nature of exchange rate regimens influences the evolution of domestic investment and FDI. Should countries that wish to encourage FDI increase the flexibility of their exchange rates, or is a fixed exchange rate regime more conducive to FDI. While existing studies have investigated the impact of exchange rate volatility on investment and intermational trade, not enough attention was given to the more fundamental forces that determine the evolution of prices, exchange rates, and the volume of trade. 2 Since investment, exchange rates, and the

1 The data for Figure 1 was taken from the IMF Balance of Payment Statistics.

2 For a discussion regarding the factors affecting FDI in recent years and the 
$-1 \mathrm{a}-$

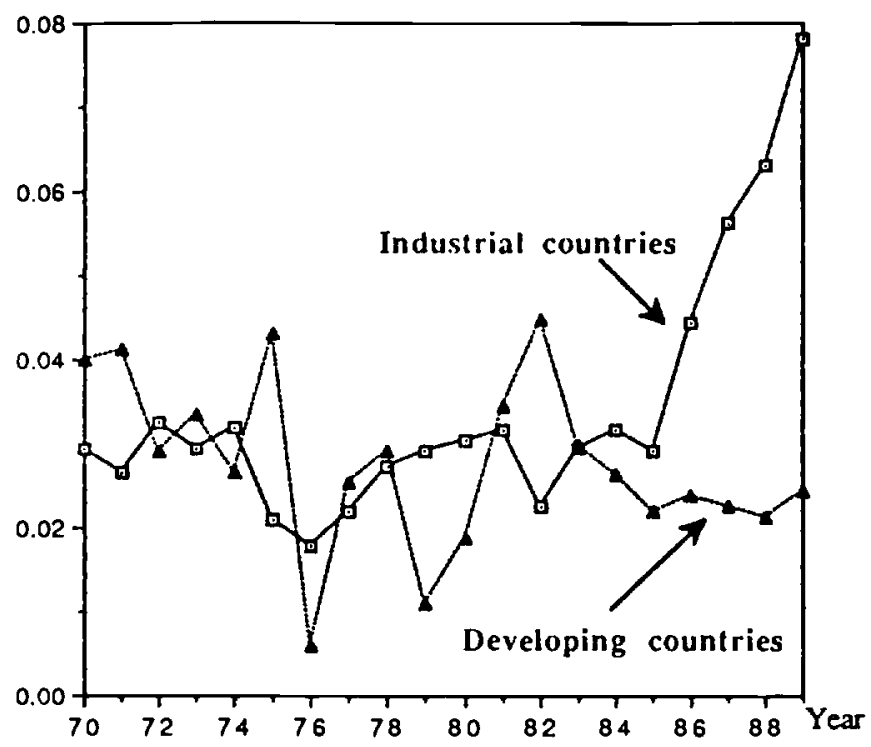

FDI / Merchandise trade in Industrial and Developing countries, 1970-1989

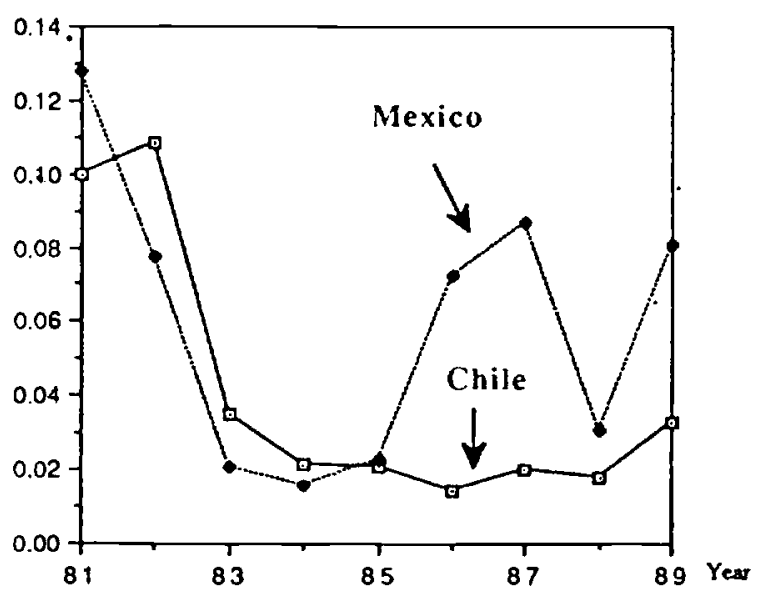

FDI / Merchandise Trade in Mexico and Chile, 1974-1989

FIGURE 1 
2 -

volume of intemational trade are endogenous variables that adjust to various shocks, their behavior can be better understood if the underlying forces affecting each economy are traced. A macroeconomic modeling strategy, where the exchange rate, prices, employment, and investment are endogenously determined may provide a more coherent interpretation to the observable correlations. The usefulness of this procedure stems from the possibility that the correlations among investment, volatility, and exchange rates differ among economies, duc to differences in structure. A purpose of this paper is to provide such a model. We apply it to identify the dependency of the correlations among observable variables on the composition of shocks, and to investigate the impact of exchange rate regimes on the behavior of investment.

To isolate the role of exchange rate regimes, we concentrate on the case where there is no impedance to intemational trade in goods or to FDI, and where agents are risk neutral. Thus, we ignore the potential role of commercial policy and transportation costs as reasons for FDI, and the possibility that the degree of risk aversion plays a role in determining the pattern of investment. We assume that labor is immobile, and installed capital is location- and sectorspecific. There is a one-period lag between the implementation of investment in productive capital and the availability of the productive capacity. "The economy is subject to productivity and monetary shocks, and the supply side is characterized by the presence of a short-run Phillips curve. FDI is motivated by the producer's attempt to increase the flexibility of production: being a multinational enables producers to reallocate employment and production towards the more efficient or the cheaper plant. This flexibility gives the producer the option to adjust its international production pattern to the realization of shocks, at the cost of carrying the extra productive capacity. 3 To address the implications of the exchange rate regime on the

implications of exchange rate volatility on investment see, for example, Froot and Stein (1989), Edwards (1990), Klein and Rosengren (1990) and Goldberg (1990).

3 A version of this model was used in Aizenman (1991) to evaluate the implications of restrictions on capital mobility on the welfare ranking of exchange rate regimes. 
$-3-$

pattern of direct investment, we construct an economy characterized by monopolistic competition, where production at a given period requires investment in the productive capacity a period ago. ${ }^{4}$ The investment is implemented by risk-free entrepreneurs, who face the option to operate as multinational or as nondiversified, national producers. We assume free entry, and hence the equilibrium is characterized by the requirement that the expected economic rent is dissipated. 5

The key outcome of our analysis is that a fixed exchange rate regime is more conducive to domestic investment and FDI relative to a flexible exchange rate; this conclusion applies for both real and nominal shocks. It is shown that, for a given characterization of shocks, the resultant investment and FDI is higher in a fixed exchange rate regime. For the case of monetary shocks, the concavity of the production function implies that volatile nominal shocks will reduce expected profits under a flexible exchange rate regime. Fixed exchange rates are capable of better isolating real wages and production from monetary shocks, and thus they are associated with lower volatility and thereby with higher expected profits. The higher expected income is, in turn, supporting higher domestic investment and FDI. For real shocks, flexible exchange rates are associated with lower volatility of employment and with lower expected profits. This conclusion stems from the observation that a country experiencing a positive productivity shock will tend to experience nominal and real appreciation, which will mitigate (and may even eliminate) the resultant employment expansion. In a fixed exchange rate system the nominal appreciation mechanism does not work, hence employment will tend to expand in

4 We construct an intertemporal version of Dixit-Stiglitz (1977) monopolistically competitive framework of the type applied by Helpman-Krugman (1989) in the international context. International transmission of disturbances in the presence of monopolistic competition and nominal rigidities has been dealt with by Dombusch (1987), Aizenman (1989) and Svensson and van Wijnbergen (1989).

5 Related models that focused on the entry-exit decisions facing entrepreneurs in the presence of volatile exchange rates are Dixit (1989) and Baldwin and Krugman (1989). 
the presence of positive productivity shock more than it does under a flexible rate. The employment expansion in the presence of a positive productivity shock under a fixed exchange rate works towards increasing expected profits, raising thereby the productive capacity, domestic investment, and FDI. 6 We also demonstrate that under a flexible exchange rate regime more volatile real shocks will increase investment and intemational trade, whereas a higher volatility of nominal shocks will reduce investment and trade. These results suggest that the sign of the correlations among exchange rate volatility, investment, and trade are determined by the mixture of the shocks affecting the economy.

In section 2 we describe the model. Section 3 characterizes the equilibrium, and Section 4 derives the closed-form solution for a simple example. Section 5 compares the various possible regimes, and Section 6 closes the discussion.

\section{The Model}

We consider a minimal model capable of addressing the above issues: a two-country, a two-period, and a two-classes-of-goods model. In the first period entrepreneurs face the investment decisions, determining the productive capacity of the economy in the second period.

We start in period one, with a given endowment of good $Y$, denoted by $\bar{Y}$. Good $Y$ serves as both the consumption and the investment good in the first period. An entrepreneur may invest in one of the two countries (operating as a nondiversified producer), or in both countries (operating as a multinational). Following the capacity decisions of the first period, entrepreneurs will use the services of labor in the second period towards the production of differentiated products, denoted by $\mathrm{D}$ and indexed by $\mathrm{i}$. We start by presenting the key

6 It is noteworthy that our analysis does not imply that a fixed exchange rate regime is superior to a flexible exchange rate system: one should compare the behavior of employment across regimes, in addition to a comparison of expected consumption. In a different context we have shown that this type of a model implies that the literature of the eighties overstated the case for a flexible exchange rate regime (see Aizenman (1991)). 


$$
-5 \text { - }
$$

behavioral assumptions of the model, describing the preferences, production, the nature of the uncertainty, and the money market.

\section{$2.1 \quad$ Preferences}

The utility of the representative agent is given by

$$
U=Y_{1}+\frac{D_{2}+g(L)}{1+\rho}
$$

where $\mathrm{L}$ denotes labor, $\mathrm{g}^{\prime}<0, \mathrm{~g}^{\prime \prime}<0$ and $\mathrm{Y}_{1}$ is the consumption of the homogeneous good at period one. The subjective rate of time preference is reflected by $\rho$, and the disutility from labor is captured by $g(L)$. The utility derived from consuming $d$ varieties of the differentiated products is given by $D_{2}$ :

$$
D_{2}=\left[\sum_{i=1}^{d}\left(D_{2, i}\right)^{\alpha}\right]^{1 / \alpha}
$$

for $0<\alpha<1$; and $p>0$. The term $D_{2 ; i}$ is the consumption level of variety $i$ in period two. Agents in the foreign country have.the same utility.

\subsection{Production}

The production of the differentiated product in plants located in the home and the foreign economy, respectively, is given by a Cobb-Douglas function:

$$
D_{2, i}^{S}=\frac{1}{a}(L) \gamma ; D_{2, i}^{S^{*}}=\frac{1}{a^{*}}\left(L^{*}\right)^{\gamma} \quad \text { for } 0<\gamma<1
$$

In order to deal with macro issues we would like to model a short-run Phillips curve, 
where nominal disturbances are transmitted into the real economy in the short run. We adapt here the Fischer-Gray formulation of labor contracts, where labor is employed subject to nominal contracts. The wage for period two is preset at level $W_{0}$, so that the expected

employment equals the employment target, $\bar{L}$. Within the second period, employinent is demand-detcrmined: producers demand labor so as to maximize their profits. ${ }^{7}$ Henceforth, foreign values are indexed by an asterisk.

\subsection{Investment, Uncertainty and the Producer's Problem}

The investment is location- and product-specific, allowing the production of the differentiated product $i$ at the chosen location. An entrepreneur may invest in one of the two countries, at a cost of $\mathrm{K}$. Altematively, entrepreneurs may diversify their productive capacity, by investing both at home and in the foreign country at a cost of $K(1+\eta)$, for $\eta \leq 1$. A diversified producer operates as a multinational firm, having the capacity to produce his variety in both countries. 8 Entrepreneurs are risk neutral, and there is free entry. The uncertainty pertains to the future productivity of labor and the supply of money in each economy. The joint distribution of the shocks is symmetric, and is known to all agents in period one. Investment is implemented at period one, prior to the resolution of the uncertainty

7 See Gray (1976) and Fischer (1977). For applications of the. Fischer-Gray framework in an open economy see, for example, Flood and Marion (1982), Turnovsky (1983) and Marston and Turnovsky (1985). It is noteworthy that there are altemative ways of modeling the short-run Phillips curve. For example, one can apply Lucas's framework of incomplete contemporaneous information regarding the decomposition of the aggregate shock into the real and the nominal parts. The key results of our approach can be delivered in such an alternative framework.

8 The value of $1-\eta$ measures the returns to scale, associated with the presence of fixed costs that may be shared by both locations. 


\section{$-7-$}

regarding the productivity in period two. A strategy of diversifying the investment can be viewed as "buying" the option of channeling production to the more productive location. More formally, let us denote the real gross profits (revenue minus the wage bill) of a diversified and a specialized producer by $\pi^{\mathrm{d}}$ and $\pi^{\text {nd }}$, respectively. A nondiversified equilibrium, where all producers specialize in one location, can be characterized by

(4a) $\quad E\left[\pi^{n d}\right]=K(1+\rho)$

(4b) $\quad E\left[\pi^{d}\right]<K(1+\rho)(1+\eta)$

where $\mathrm{E}$ stands for the expectation operator, referring to the first-period expected level of second-period profits. Equation (4a) is generated by the free entry, implying the break-even condition. Condition (4b) implies that the marginal producer does not have an incentive to diversify internationally. Integrating the two conditions we infer that a nondiversified equilibrium is stable if

(5) $\quad \frac{E\left[\pi^{d}\right]-E\left[\pi^{n d}\right]}{E\left[\pi^{n d}\right]}<\eta$

Equation (5) indicates that the (percentage) gain from diversification falls short of the percentage increase of costs. Applying the same logic, the diversified equilibrium is characterized by

(6a) $\quad E\left[\pi^{d}\right]=K(1+\rho)(1+\eta)$

(6b) $\quad E\left[\pi^{n d}\right]<K(1+\rho)$

Or, that ${ }^{9}$

9 The intermediate case, where producers will be indifferent between the two investment strategies, will occur if all the inequalities in (5) and (6) are replaced with 


$$
\text { (7) } \quad \frac{E\left[\pi^{d}\right]-E\left[\pi^{n d}\right]}{E\left[\pi^{n d}\right]}>\eta
$$

\subsection{The Money Market:}

To simplify exposition, we adapt the simplest specification of the demand for money: a constant velocity specification where the demand for money equals a fraction $q$ of the nominal domestic GNP, and for notation simplicity we assume $q=1$. Under a fixed exchange rate regime, the national money markets are integrated into a unified international money market. The equilibrium is characterized by the equality of the global demand and supply of money, where the balance of payment mechanism generates the desirable distribution of money across countries. Under a flexible exchange rate system the money market is national, and domestic prices and the exchange rate are determined so as to equate the demand and the supply of money at each country.

\section{The Equilibrium}

The equilibrium can be analyzed by first characterizing the consumer's and producer's behaviors, and then by describing, the possible regimes.

\subsection{Consumer's Demand}

Consumption in the second period is characterized by the solution to

$$
\begin{array}{ll}
\operatorname{Max} & {\left[\sum_{i=1}^{\mathrm{d}}\left(\mathrm{D}_{2, \mathrm{i}}\right)^{\alpha}\right]^{1 / \alpha}} \\
\text { s.t. } & \sum_{\mathrm{i}=1}^{\mathrm{d}} \mathrm{P}_{2, \mathrm{i}} \mathrm{D}_{2, \mathrm{i}}=\mathrm{IN}_{2}
\end{array}
$$

equalities. 
where $P_{2 ; i}, I N_{2}$ are the second-period money prices of good $i$ and the second-period money income, respectively. The solution of the consumer's problem is characterized by

$$
\mathrm{D}_{2, \mathrm{i}}=\left(\frac{\overline{\mathrm{P}}_{2}}{\mathrm{P}_{2, \mathrm{i}}}\right)^{\sigma} \frac{\mathrm{IN}_{2}}{\overline{\mathrm{P}}_{2}}
$$

for $\sigma=1 /(1-\alpha)$ and

$$
\overline{\mathrm{P}}_{2}=\left[\sum_{\mathrm{i}=1}^{\mathrm{d}}\left(\mathrm{P}_{2, \mathrm{i}}\right)^{-\alpha \sigma}\right]^{-1 /(\alpha \sigma)}
$$

The overall price index of differentiated products is $\overline{\mathrm{P}}_{2}$. The consumer's utility function (1) is additive in the consumption of the homogeneous good in period one and the consumption of the differentiated products aggregate $D_{2}$. Applying (9) and (10) it follows that $D_{2}=$

IN $/ \vec{P}_{2}$. This implies that if we observe an internal equilibrium where goods are consumed in both periods, the real interest rate in terms of good $\mathrm{Y}$ must equal $1+\rho$. At that interest rate, consumers are willing to postpone consumption to the second period, and the aggregate saving is determined by the investment. Henceforth we assume that the supply of the homogeneous good is large enough to induce an internal equilibrium. 10

10 Note that the assumption of risk-neutral entrepreneurs implies that investment $I$ in period one, generating nominal income $\Pi_{2}$ in the second period, will be undertaken if $E\left[\Pi_{2} / \bar{P}_{2}\right]-I(1+\rho) \geq 0$. It can be shown that if the supply of $Y$ is small enough, the Cobb-Douglas production function (defined by (3)) implies a comer solution where all $\mathrm{Y}$ is invested, and none is consumed in the first period. In such a case, the real interest rate is 


\subsection{Producer's Pricing}

The producer of a differentiated product $i$ has market power, facing a demand, the elasticity of which is $\sigma$ (see (9)). The condition for maximizing profits is that the value of the marginal product of labor (given by the product of the marginal revenue and the marginal product of labor) equals the wage. Applying (3) and (9) we can infer that the resultant supply of the differentiated product and the demand for labor (denoted by $D_{2 ; i}$ and $L_{2 ; i}^{d}$, respectively) are

$$
D_{2, i}^{S}=a^{-1 /(1-\gamma)}\left(\frac{\alpha \gamma P_{2, i}}{W_{0}}\right)^{\gamma^{\prime}} \quad ; \quad L_{2, i}^{d}=\left(\frac{\alpha \gamma P_{2, i}}{a W_{0}}\right)^{1 /(1-\gamma)}
$$

where $\gamma^{\prime}=\frac{\gamma}{1-\gamma}$. The producers' nominal profits (denoted by $\Pi_{2 ; i}$ ) are

$$
\Pi_{2, \mathrm{i}}=(1-\alpha \gamma) \mathrm{P}_{2, \mathrm{i}} \mathrm{D}_{2, \mathrm{i}}
$$

We tum now to characterize the equilibrium in a fixed and a flexible exchange rate regime. The two countries are identical ex ante, hence we focus on the symmetric equilibrium.

\subsection{Fixed Exchange Rate Regime}

We normalize the exchange rate to unity, and assume away transportation costs and commercial policy. Thus, the price of the same variety is the same in both countries. We contrast first the case where all producers are nondiversified, specializing in one country,

determined by the marginal productivity of capital. If the supply of $Y$ is large enough to ensure positive consumption in period one, the real interest rate is determined by preferences $(=1+\rho)$. In such a case, the actual investment is determined by the demand for investment at that real interest rate. 


$$
-11-
$$

versus the case where all producers operate as multinationals. Having accomplished this, we may characterize the edge knife cases of a mixed regime, where both multinationals and specialized producers operate, as borderline combinations of the above cases.

\subsubsection{Nondiversified Producers:}

If all producers operate as nondiversified in a symmetric equilibrium, $m$ producers specialize in the production of distinct varieties in each country, and the total number of goods is $2 \mathrm{~m}$. The equilibrium is characterized by the following conditions:

$$
\begin{aligned}
& \text { a. } \quad a-1 /(1-\gamma)\left(\frac{\alpha \gamma P_{2, i}}{W_{0}}\right)^{\gamma^{\prime}}=\left(\frac{\bar{P}_{2}}{P_{2, i}}\right)^{\sigma} \frac{I_{2}+N_{2}}{\bar{P}_{2}} \quad, \quad i=1, \ldots m \\
& \left(a^{*}\right)^{-1 /(1-\gamma)}\left(\frac{\alpha \gamma P_{2, j}^{*}}{W_{0}}\right)^{\gamma^{\prime}}=\left(\frac{\bar{P}_{2}}{P_{2, j}}\right)^{\sigma} \frac{I_{2}+I_{2}^{*}}{\bar{P}_{2}}, j=1, \ldots, m . \\
& \text { b. } \quad \bar{P}_{2}=(m)^{-1 /(\alpha \sigma)}\left(\left(\mathrm{P}_{2 ; \mathrm{r}}\right)^{-\alpha \sigma}+\left(\mathrm{P}_{2, \mathrm{r}^{*}}\right)^{-\alpha \sigma}\right)^{-1 /(\alpha \sigma)} \\
& \text { c. } \quad \mathrm{IN}_{2}=\mathrm{m} \mathrm{P}_{2, \mathrm{r}} \mathrm{D}_{2, \mathrm{r}}^{\mathrm{S}} ; \quad \mathrm{IN}_{2}^{*}=\mathrm{mP}_{2, \mathrm{r}^{*}} \mathrm{D}_{2, \mathrm{r}^{*}}^{\mathrm{s}^{*}} \\
& \text { d. } \quad \mathrm{IN}_{2}+\mathrm{IN}_{2}^{*}=\mathrm{M}_{2}^{\mathrm{s}}+\mathrm{M}_{2}^{\mathrm{s}} \\
& \text { e. } \quad m E\left[L_{2, i}^{d}\right]=\bar{L} \\
& \text { f. } \quad E\left[(1-\alpha \gamma) \frac{P_{2, i} D_{2, i}^{s}}{\bar{P}_{2}}\right]=K(1+\rho)
\end{aligned}
$$

Condition (13a) is the goods market equilibrium, equating the supply to the sum of the domestic and the foreign demand (as inferred from (9) and (11)). A similar condition applies 
for foreign varieties. Equation (13b) is the consumer CPI index, obtained from (10), where $r$ and $r^{*}$ stand for a representative variety produced at home and abroad. The nominal income equals the nominal GNP, as given by (13c). Recalling that we assumed a unitary velocity, the equilibrium in the global money market is stated in (13d), where index s stands for the supply. Applying the Fischer-Gray macro framework, the wage contract is set according to (13e), 10 equate the expected employment to the employment target. Free entry implies that net rents are zero, as is postulated by (13f).

\subsubsection{Multinational Producers:}

Applying similar considerations, if all producers are multinational, and there are $\mathrm{n}$ of them, the equilibrium will be characterized by

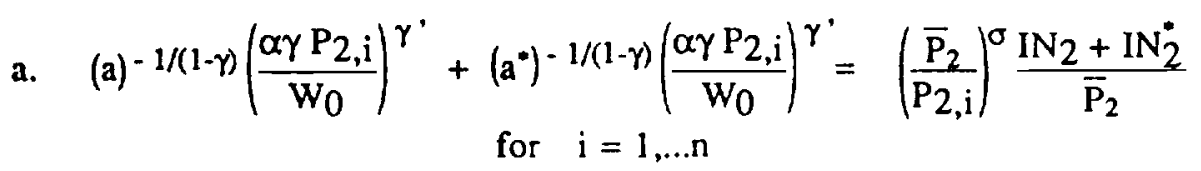

b. $\quad \bar{P}_{2}=n-1 /(\alpha \sigma) P_{2 ; r}$

(14)

c. $\quad \mathrm{IN}_{2}=\mathrm{n} \mathrm{P}_{2, \mathrm{r}} \mathrm{D}_{2, \mathrm{r}}^{\mathrm{s}} ; \quad \mathrm{IN}_{2}^{*}=\mathrm{nP}_{2, \mathrm{r}} \mathrm{D}_{2, \mathrm{r}}^{\mathrm{s}}$

d. $\quad \mathrm{IN}_{2}+\mathrm{IN} \mathrm{N}_{2}^{*}=\mathrm{M}_{2}^{\mathrm{S}}+\mathrm{M}_{2}^{\mathrm{S}^{*}}$

e. $\quad n \in[L d, i]=\bar{L}$

f. $\left.\quad E(1-\alpha \gamma) \frac{P_{2, i}\left\langle D_{2, i}^{s}+D_{2, i}^{*} s\right|}{\bar{P}_{2}}\right]=K(1+\eta)(1+\rho)$

Multinational producers will produce in both countries; thus the supply of each good is the sum 
of the production in plants located in both countries (as indicated by (14a)). The CPI is modified in accordance with the presence of goods produced simultaneously in both countries. The zero expected rents condition (14f) recognizes that profits are due to production in both locations, and that the cost of capital goes up (at a rate of $\eta$ ) due to the needed investment in two plants. In addition to the conditions postulated in (13) and (14), stability conditions determine the nature of the regime. We observe a nationalistic equilibrium where all producers specialize in one location, if the marginal benefit from becoming multinational falls short of the extra capacity cost, and thus a version of (5) should be satisfied. Similarly, we will observe a multinational equilibrium if producers will not benefit by switching to a nationalistic strategy, and thus a version of (7) applies. We turn now to characterize the equilibrium in a flexible exchange rate regime.

\subsection{Flexible Exchange Rate Regime}

With a flexible exchange rate the money market clears in each country separately, determining the price levels in the two economies and indirectly the exchange rate. We denote the exchange rate by $S$, defined as the domestic currency price of a unit of foreign currency. The law of one price is assumed to hold for the same variety, and thus $P_{2, i}=S P_{2, i}^{*}$, where $\dot{P}_{2, i}$ stands for the foreign currency price of variety $i$ abroad. The modified equilibrium conditions are 


\subsubsection{Nondiversified Producers}

a. $\quad(\mathrm{a})^{-1 /(1 \cdot \gamma)}\left(\frac{\alpha \gamma \mathrm{P}_{2, \mathrm{i}}}{\mathrm{W}_{0}}\right)^{\gamma^{\circ}}=\left(\frac{\overline{\mathrm{P}}_{2}}{\mathrm{P}_{2, \mathrm{i}}}\right)^{\sigma} \frac{\mathrm{IN} 2+\mathrm{S} \mathrm{IN}}{\overline{\mathrm{P}}_{2}}, \mathrm{i}=1, \ldots, \mathrm{m}$ $\left(\mathrm{a}^{*}\right)^{-1 /(1-\gamma)}\left(\frac{\alpha \gamma \mathrm{P}_{2, \mathrm{j}}^{*}}{\mathrm{~W}_{0}}\right)^{\gamma^{\prime}}=\left(\frac{\overline{\mathrm{P}}_{2}}{S \mathrm{P}_{2, \mathrm{j}}^{*}}\right)^{\sigma} \frac{\mathrm{IN}_{2}+\mathrm{S} I \mathrm{~N}_{2}^{*}}{\overline{\mathrm{P}}_{2}}, \mathrm{j}=1, \ldots, \mathrm{m}$

b. $\left.\quad \bar{P}_{2}=(m)^{-1 /(\alpha \sigma)}\right)\left(\mathrm{P}_{2 ; \mathrm{r}}\right)^{-\alpha \sigma}+\left.\left(S \mathrm{P}_{2, \mathrm{r}^{*}}\right)^{-\alpha \sigma}\right|^{-1 /(\alpha \sigma)}$

(15)

c. $\quad \mathrm{IN}_{2}=\mathrm{m} \mathrm{P} \mathrm{P}_{2, \mathrm{r}} \mathrm{D}_{2, \mathrm{r}}^{\mathrm{S}} ; \quad \mathrm{IN}_{2}^{*}=\mathrm{m} \mathrm{P}_{2, \mathrm{r}^{*}}^{*} \mathrm{D}_{2, \mathrm{r}^{*}}^{\mathrm{s}^{*}}$

d. $\quad \mathrm{IN}_{2}=\mathrm{M}_{2}^{\mathrm{S}} ; \mathrm{IN}_{2}^{*}=\mathrm{M}_{2}^{\mathrm{s}^{*}}$

e. $\quad m E\left[L_{2, i}^{d}\right]=\bar{L}$

f. $\quad E\left[(1-\alpha \gamma) \frac{P_{2, i} D_{2, j}^{S}}{\bar{P}_{2}}\right]=K(1+\rho)$

\subsubsection{Multinational Producers}

An equilibrium under a flexible exchange rate regime, where all producers are multinational, is characterized by

$$
\begin{aligned}
& \text { a. (a) }-1 /\left(1-\gamma\left(\frac{\alpha \gamma P_{2, i}}{W_{0}}\right)^{\gamma^{\prime}}+\left(a^{*}\right)-1 /(1-\gamma)\left(\frac{\alpha \gamma P_{2, i}}{S W_{0}}\right)^{\gamma^{\prime}}=\left(\frac{\bar{P}_{2}}{P_{2, i}}\right)^{\sigma} \frac{I N_{2}+S I N_{2}^{*}}{\bar{P}_{2}}\right. \\
& \text { b. } \quad \bar{P}_{2}=(n)-1 /(\alpha \sigma) P_{2 ; r} \\
& \text { (16) c. } \quad I_{2}=n P_{2, r} D_{2, r}^{S} ; \quad S I N_{2}^{*}=n P_{2, r} D_{2, r}^{s^{*}}
\end{aligned}
$$




$$
\begin{array}{ll}
\text { d. } & \mathrm{IN}_{2}=\mathrm{M}_{2}^{\mathrm{S}} ; \mathrm{IN}_{2}^{*}=\mathrm{M}_{2}^{\mathrm{s}^{*}} \\
\text { e. } & \mathrm{nE}\left[\mathrm{L}_{2, \mathrm{i}}^{\mathrm{d}}\right]=\overline{\mathrm{L}} \\
\text { f. } & \mathrm{E}\left[(1-\alpha \gamma) \frac{\mathrm{P}_{2, \mathrm{i}}\left\{\mathrm{D}_{2, \mathrm{i}}^{\mathrm{s}}+\mathrm{D}_{2, \mathrm{i}}^{*} \mathrm{~s}\right\}}{\overline{\mathrm{P}}_{2}}\right]=K(1+\eta)(1+\rho)
\end{array}
$$

We now characterize the equilibrium for a simple example.

\section{Real and Nominal Shocks, Volatility, and Investment}

Further insight is gained by focusing on the simplest stochastic example: two states of nature, with a negative correlation between the domestic and foreign shocks. 11 Exposition is simplified further by considering the extreme cases, where all shocks are either real or nominal. When we understand these two extreme cases, we can redo the analysis for the general case.

\subsection{Real Shocks:}

Suppose first that the volatility is due to productivity shocks, which can obtain the following values:

(17) $\left(\frac{1}{\mathrm{a}}, \frac{1}{\mathrm{a}^{*}}\right)=\{$ or

$$
(1+h, 1-h)
$$

$$
(1-h, 1+h) \text {, with equal probabilities }(1>h>0) \text {. }
$$

11 The simplicity of the example enables us to focus on a closed-form solution, discarding the need to use first-order approximations. While being a special example, it allows us to describe the economic forces at work. Our results can be shown to apply to richer stochastic environments, with any number of states of nature. Our analysis can be readily extended to the case of a positive correlation. 


\subsubsection{Eixed Exchange Rate Regime. Real Shocks:}

Solving the systems summarized in (13) and (14) we infer that investment in the nondiversified and the multinational regimes is given by:

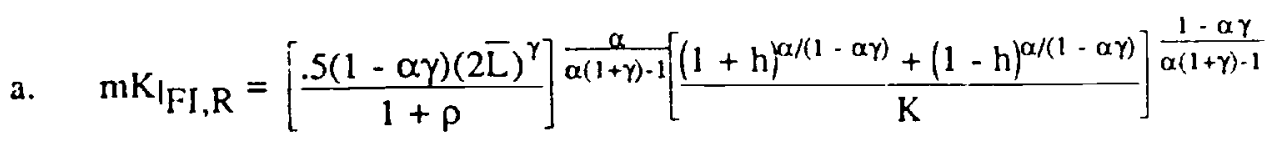

b.

$.5 \mathrm{nK}(1+\eta)_{\mathrm{FI}, \mathrm{R}}=.5\left[\frac{(1-\alpha \gamma)(2 \overline{\mathrm{L}})^{\gamma}\left((1+h)^{1 /(1-\gamma)}+(1-h)^{1 /(1-\gamma))^{1-\gamma}}\right.}{1+\rho}\right]^{\frac{\alpha}{\alpha(1+\gamma)-1}}\left[\frac{1}{\mathrm{~K}(1+\eta)}\right]^{\frac{1-\alpha \gamma}{\alpha(1+\gamma)-1}}$

where IFI, R stands for fixed exchange rate, subject to real shocks. The condition determining the nature of the regime is obtained by applying (5), yielding the result that producers will operate as nondiversified if $h$ is small enough that 12

(19) $\left[(1+h)^{1 /(1-\gamma)}+(1-h)^{1 /(1-\gamma)}\right]_{1-\alpha \gamma}^{\alpha(1-\gamma)}<(1+\eta) .5\left[(1+h)^{\alpha /(1-\alpha \gamma)}+(1-h)^{\alpha /(1-\alpha \gamma))}\right]$

and diversification will occur if the opposite inequality holds. There are two possible reasons for diversification: retums to scale, and the gains originating from the option of reallocating production towards the more productive country. Internationally diversified capacity will allow spreading production across several plants, mitigating the impact of the diminishing

12 In (5), $E\left[\pi^{n d}\right]=E\left[(1-\alpha \gamma) \frac{P_{2, i} D_{2, i}^{S}}{\bar{P}_{2}}\right]$. The value of $E\left[\pi^{d}\right]$ is obtained by calculating the profits that will occur to a marginal producer that will switch to a multinational strategy. This is found by using a version of $(14 a)$ for the case where all other producers hehave as specified in (13). 
$-17$.

marginal productivity at a cost of increasing the capital expenditure by factor $\eta$. If this cost is small enough, it will be worthwhile to invest in multiple plants. Formally, we obtain from (18) that if $2^{\alpha(1-\gamma) /(1-\alpha \gamma)}-1>\eta$, then producers will diversify independently of volatility. If this condition is not satisfied, international diversification will occur if volatility (as measured by $h$ ) is high enough. A higher volatility increases the economic value of the diversification, by increasing the value of the option to reallocate production towards the more productive or the cheaper country. Diversification will occur if the value of this option exceeds the extra cost of capital, as will occur if the inequality in (19) is reversed. Inspection of (19) shows that as long as $1>\eta$, for large enough $h$ producers will diversify intemationally. Henceforth, we will assume that $2^{\alpha(1-\gamma) /(1-\alpha \gamma)}-1<\eta<1$. Hence, in the absence of uncertainty producers will specialize.

\subsubsection{Flexible Exchange Rate Regime, Real Shocks:}

Solving the systems summarized in (15) and (16) we infer that investment in the nondiversified and the multinational regimes is given by

a. $\quad \mathrm{mK}_{\mathrm{IFL}, \mathrm{R}}=\left[\frac{.5(1-\alpha \gamma)(\overline{\mathrm{L}})^{\gamma}}{1+\rho}\right]^{\frac{\alpha}{\alpha(1+\gamma)-1}}\left[\frac{(1+\mathrm{h})^{\alpha}+(1-\mathrm{h})^{\alpha} \frac{1}{1 \cdot \alpha \gamma}}{\mathrm{K}}\right]^{\frac{1-\alpha \gamma}{\alpha(1+\gamma)-1}}$

(20).

b. $\left.\quad .5 \mathrm{nK}(1+\eta)\right|_{\mathrm{FL}, \mathrm{R}}=.5\left[\frac{2(1-\alpha \gamma)(\overline{\mathrm{L}})^{\gamma}}{1+\rho}\right]^{\frac{\alpha}{\alpha(1+\gamma) \cdot 1}}\left[\frac{1}{\mathrm{~K}(1+\eta)}\right]^{\frac{1-\alpha \gamma}{\alpha(1+\gamma) \cdot 1}}$

where index FL, $R$ stands for a flexible exchange rate, in the presence of real shocks. Applying (5) we infer that producers will operate as nondiversified if and only if $h$ is small enough, in such a way that

(21) $\left[(1+h)^{(1-\alpha \gamma) /(1-\gamma)}+(1-h)^{(1-\alpha \gamma) /(1-\gamma)} \frac{\alpha(1-\gamma)}{1-\alpha \gamma}<(1+\eta) .5\left[(1+h)^{\alpha}+(1-h)^{\alpha}\right]\right.$ 
-18 -

and diversification will occur if the opposite inequality holds. Similarly to the case of the fixed exchange rate, the condition for observing a nondiversified regime in the absence of volatility is that $2^{\alpha(1-\gamma) /(1-\alpha \gamma)}-1<\eta$.

We will henceforth assume that the various heterogeneous goods are close substitutes, and that the labor share is large enough that $1 /(1+\gamma)<\alpha$. This assumption is needed in order to insure that a higher set-up cost $\mathrm{K}$ will reduce the number of varieties offered. 13 Applying (18), (20) it can be shown that

$$
\begin{gathered}
\mathrm{mK}_{\left.\right|_{\mathrm{FL}, \mathrm{R}}}<\mathrm{mK}_{\left.\right|_{\mathrm{FI}, \mathrm{R}}} \\
\text { (22) } .5 \mathrm{n}(1+\eta) \mathrm{K}_{\left.\right|_{\mathrm{FL}, \mathrm{R}}}<.5 \mathrm{n}(1+\eta) \mathrm{K}_{\mathrm{I}_{\mathrm{FI}, \mathrm{R}}}
\end{gathered}
$$

and that the switch from nondiversified to a multinational investment strategy occurs in a fixed exchange rate regime at a lower volatility than in a flexible exchange rate system.

\subsection{Monetary Shocks}

We turn now to evaluate the adjustment to a monetary disturbance. Suppose that the supply of money is given by

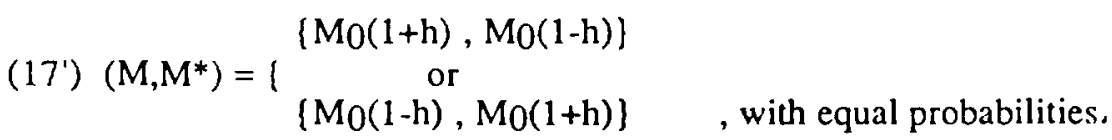

where $M$ and $M^{*}$ stand for nominal balances in the two countries.

13 It can be shown that the elasticity of expected real profits with respect to the number of varieties is $[1-\alpha(1+\gamma)] / \alpha$. If the demand for the various varieties is relatively inelastic, more varieties will reduce the labor employed in the production of a representative variety, raising thereby profits. This will have the consequence that profits will go up with the number of varieties, and that a higher setup cost will imply more producers. The assumption that the varieties are close substitutes rules out this outcome. 


\subsubsection{Fixed Exchange Rate Regime. Nominal Shocks:}

Solving the systems summarized in (13) and (14), we infer that investment in the nondiversified and the multinational regimes is given by

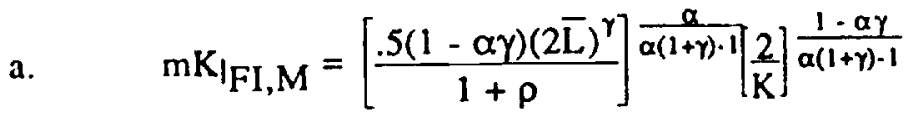

b. $\left.\quad .5 n K(1+\eta)\right|_{F I, M}=.5\left[\frac{2(1-\alpha \gamma)(\bar{L})^{\gamma}}{1+\rho}\right]^{\frac{\alpha}{\alpha(1+\gamma)-1}}\left[\frac{1}{K(1+\eta)}\right]^{\frac{1-\alpha \gamma}{\alpha(1+\gamma) \cdot 1}}$

where IFI,M stands for fixed exchange rate, subject to monetary shocks. The condition determining the nature of the regime is obtained by applying (5), yielding that producers will operate as nondiversified if and only if $2^{\alpha(1-\gamma) /(1-\alpha \gamma)}-1<\eta$.

\subsubsection{Flexible Exchange Rate Regime Nominal shocks:}

Solving the systems summarized in (15) and (16), we infer that investment in the nondiversified and the multinational regimes is given by

$$
\mathrm{mK}_{\mid F L, M}=\left[\frac{.5(1-\alpha \gamma)(\bar{L})^{\gamma}}{1+\rho}\right] \frac{\alpha}{\alpha(1+\gamma)-1}\left[\frac{(1+h)^{\alpha \alpha \gamma}+(1-h)^{\alpha \gamma} \mid \frac{1}{1-\alpha \gamma}}{K}\right]^{\frac{1-\alpha \gamma}{\alpha(1+\gamma) \cdot 1}}
$$

a.

$$
.5 n K(1+\eta) \mid F L, M=.5\left[\frac{\left.(1-\alpha \gamma)(\bar{L})^{\gamma} \mid(1+h)^{\gamma}+(1-h)^{\gamma}\right)}{1+\rho}\right]^{\frac{\alpha}{\alpha(1+\gamma)-1}}\left[\frac{1}{K(1+\eta)}\right] \frac{1 \cdot a \gamma}{\alpha(1+\gamma)-1}
$$

where index /FL,M stands for a flexible exchange rate regime, in the presence of monetary shocks. Applying (5) we infer that producers will operate as nondiversified if and only if $h$ is small enough, so that 
(25)

$$
\left[(1+h)^{(1-\alpha \gamma) \gamma /(1-\gamma)}+(1-h)^{(1-\alpha \gamma) \gamma /(1-\gamma)]_{1-\alpha \gamma}^{\alpha(1-\gamma)}}<(1+\eta) .5\left[(1+h)^{\alpha \gamma}+(1-h)^{\alpha \eta} \eta\right.\right.
$$

and diversification will occur if the opposite inequality holds. Similarly to the case of the fixed exchange rate, the condition for observing a nondiversified producer is that the international return to scale is not powerful, so that $2^{\alpha(1-\gamma) /(1-\alpha \gamma)}-1<\eta$.

Comparing (23) and (25) we infer that

$$
\begin{aligned}
\mathrm{mK}_{\mathrm{I}_{\mathrm{FL}, \mathrm{M}}} & <\mathrm{mK}_{\mathrm{I}_{\mathrm{FI}, \mathrm{M}}} \\
\text { (26) } .5 n(1+\eta) \mathrm{K}_{\mathrm{FL}_{\mathrm{F}, \mathrm{M}}} & <.5 \mathrm{n}(1+\eta) \mathrm{K}_{\mathrm{IFI}_{\mathrm{M}} \mathrm{M}}
\end{aligned}
$$

We turn now to evaluate the patterns of investment.

\section{Comparison Among Regimes}

We tum now to a graphic summary of the results, and an economic interpretation of the findings. The comparison among regimes is done by tracing the dependency of aggregate investment on the volatility of shocks. The aggregate investment for each country is given by $\mathrm{mK}+.5 \mathrm{nK}(1+\eta)$, whereas the volatility measure is $h$. The assumption of risk-ncutral entrepreneurs, and the fact that gross profits are a fraction $1-\alpha \gamma$ of revenue imply that the expected utility from consumption is given by 14

14 We obtain this result in several steps. First, we note that the first period budget constraint is $Y_{1}=\bar{Y}-m K-.5 \mathrm{nK}(1+\eta)$. From (9) and (10) we infer that that $D_{2}=$ $\mathrm{IN}_{2} / \overline{\mathrm{P}}_{2}$, where $\mathrm{IN}_{2}$ is the nominal GNP. Equation (27) is inferred by applying this result 


$$
E\left[Y_{1}+\frac{D_{2}}{1+\rho}\right]=\bar{Y}+\frac{\alpha \gamma}{1-\alpha \gamma}[m K+.5 n K(1+\eta)]
$$

Consequently, tracing the behavior of aggregate investment gives us information regarding the expected utility of consumption, or equivalently the expected net present value of real consumption. 15 In our model trade accounts (on average) for half of the GNP, and thus tracing the expected consumption provides us also with information regarding the average volume of international trade.

Figures $2 \mathrm{a}$ and $2 \mathrm{~b}$ summarize the dependency of the productive capacity on the volatility of shocks for real and nominal disturbances, respectively. Curves denoted by FI, FL correspond to fixed and flexible exchange rate regimes, and $\mathrm{N}$ and $\mathrm{D}$ correspond to nondiversified and diversified regimes, respectively. The figures reveal that for a given volatility of the shocks, a fixed exchange rate regime is associated with higher domestic investment and FDI, relative to a flexible exchange rate. While the figures are drawn for the special example considered here, its underlying logic is more general. With free entry, the behavior of aggregate investment traces the behavior of gross profit, which on average is the retum to capital. For a given volatility of shocks, a fixed exchange rate regime is associated with higher expected profits. If the shocks are monetary, then employment will fluctuate more under a flexible exchange rate regime. In fact, in our example employment will be stable under a fixed exchange rate. The volatility of employment and production under a floating exchange rate will depress expected profits. This argument is traced in Figure 3, where the production function in the absence of real shocks is given by $\mathrm{D}_{\mathrm{i}}^{\mathrm{s} ; 0}$. The impact of volatility

and (13f), (14f), (15f), (16f), calculating the expected utility of consumption.

15 Note that (27) represents only the consumption component of the expected utility. To obtain the expected utility, one must subtract from (27) the expected disutility from labor. 


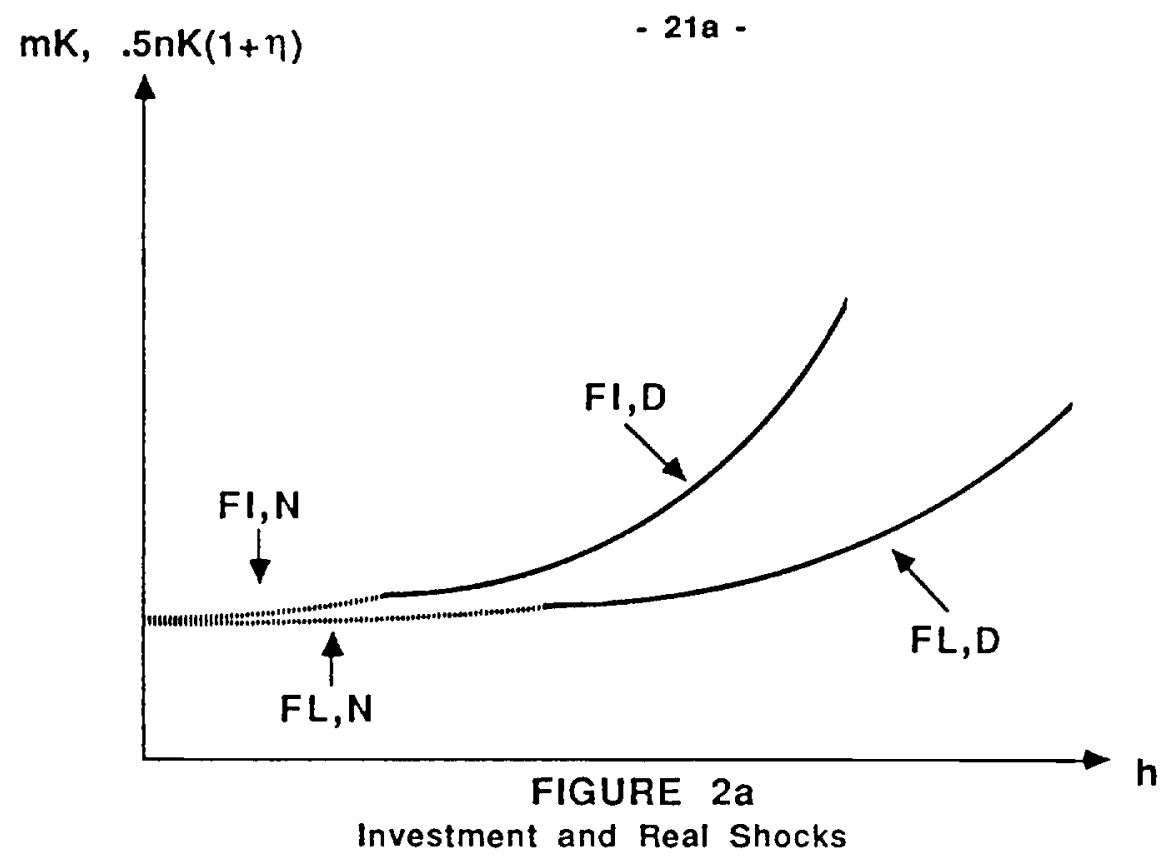

FI

$m K, \quad .5 n K(1+\eta)$

FIGURE $2 b$

Investment and Nominal Shocks

$F L=$ flexible exchange rate; $F I=$ fixed exchange rate;

$D=$ diversified producers $; N=$ non diversified prducers 
due to monetary shocks in a flexible exchange rate system is that employment will fluctuate between $\mathrm{L}_{l}$ and $\mathrm{L}_{h}$ (where $\mathrm{L}_{h}-\overline{\mathrm{L}}=\overline{\mathrm{L}}-\mathrm{L}_{l}$ ). This will depress expected profits, from point $\mathrm{K}_{2}$ to point $\mathrm{K}_{3}$.

The case of real shocks is more involved, because the production function shifts around the non- stochastic production, fluctuating between $\mathrm{D}_{\mathrm{i}}^{\mathrm{s} ; h}$ and $\mathrm{D}_{\mathrm{i}}^{s ; l}$ in the state of high and low productivity, respectively. If we operate in the regimes where all producers diversify, in a fixed exchange rate regime we will observe reallocation of employment from the less productive towards the more productive country. This reallocation is smaller in a flexible exchange rate regime because the country experiencing the more favorable realization of productivity will experience nominal and real appreciation, which will mitigate (and potentially eliminate) the resultant expansion of employment. In fact, in our case a flexible exchange rate eliminates the volatility of employment. The greater reallocation of employment towards the more efficient country in a fixed exchange rate regime will tend to increase expected profits, thereby encouraging investment. In terms of Figure 3, employment will fluctuate between $\mathrm{L}_{l}$ and $\mathrm{L}_{h}$ in a fixed exchange rate regime, and will stay at $\overline{\mathrm{L}}$ in a flexible exchange rate regime. The reallocation of employment observed in a fixed exchangc rate regime increases expected output. To see this, note that the marginal product of labor at point A exceeds that at point $B$ by a factor of $2 h$. Thus, starting with employment level $\bar{L}$ in both countries under a fixed exchange rate regime, a marginal reduction of employment in the less productive country and a corresponding increase in employment in the more productive country will increase expected profits by the discrepancies of the marginal product. The same logic applies to the consecutive reallocation of employment across countries, until we eliminate this arbitrage opportunity (i.e, until we reach a point like $A^{\prime}$ and $B^{\prime}$ where the marginal product is equal in the two countries). In terms of Figure 3 , this will result with expected output $K_{1}$ in a fixed exchange rate regime, exceeding the expected output in a flexible 


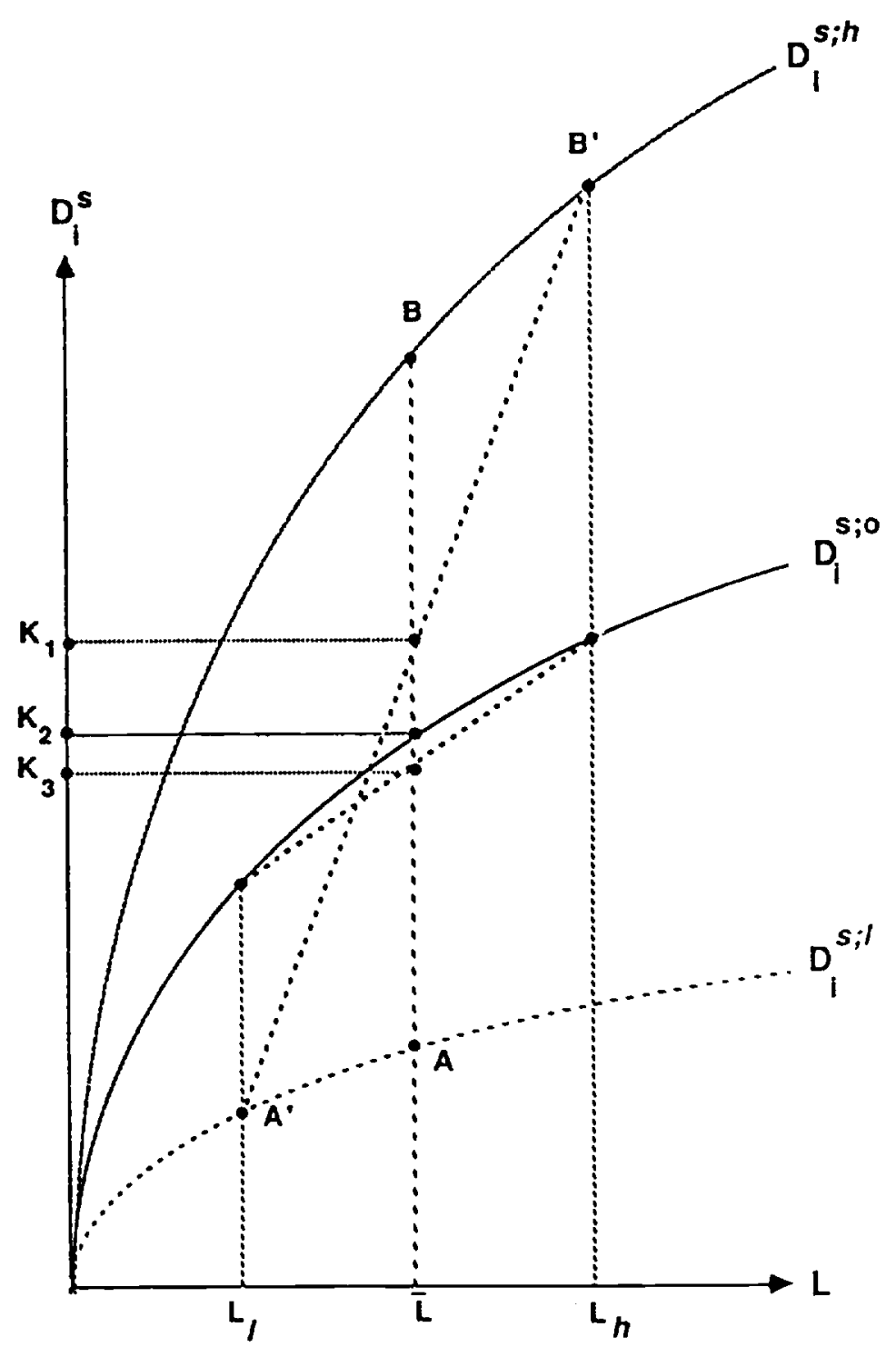

FIGURE 3 
exchange rate regime, $\mathrm{K}_{2} \cdot 16 \quad 17$

Figure 2 reveals that the correlation between investment and exchange rate volatility under a flexible exchange rate depends on the nature of shocks. Higher volatility of shocks is associated with a higher volatility of the exchange rate. Note that curves are upward-sloping in Figure 2a, downward-sloping in Figure 2b. Hence, if the dominant shocks are nominal, we will observe a negative correlation, whereas if the dominant shocks are real, we will observe a positive correlation between exchange rate volatility and the level of investment.

16 Note that the producer cares about the expected real profits. In our monopolistic competitive framework there is positive association between output and real profits, and hence higher expected output implies also higher expected profits.

17 While the above explanation was given in terms of a multinational producer, the same logic applies for the case of nationalistic producers, where the reallocation of employment should be viewed as reallocation that occurs across states of nature for a given economy. 


\section{Concluding Remarks}

Rather than repeating the summary provided in the first section, we close the paper with concluding remarks. Our analysis suggests that nominal shocks in a flexible exchange rate regime have adverse implications on investment behavior and that attempts to encourage FDI may benefit by adapting a fixed exchange rate. While we focused on the case where nominal shocks stem from the stochastic supply of money, the same analysis applies if the volatility stems from the stochastic demand for money, or from "bubbles". 18 These results suggest that attempts to minimize nominal shocks by the proper coordination of monetary policies are beneficial, and that these benefits may occur indirectly by encouraging investment. It is useful to note that our results continues to hold even if producers have access to a forward exchange rate market. The results derived in this paper stem from the absence of complete markets in the presence of contracts that do not allow for complete contingent prices. The addition of forward coverage does not solve the market incompleteness, and all the paper's results continue to hold. Finally, it is noteworthy that we assumed risk neutrality, and thus none of our results is related to risk-averse behavior. While we do not negate the potential importance of risk aversion, we view this as a useful benchmark that can be enriched to accommodate more complicated behavior.

18 See Frankel and Froot (1990) for a study that analyzed "bubbles" as a potential driving force in the evolution of exchange rates. 


\section{References}

Aizenman, Joshua, "Foreign Direct Investment, Productive Capacity and Exchange Rate Regimes," NBER Working paper N0. 3767, July 91.

"Monopolistic Competition, Relative Prices, and Output Adjustment in the Open Economy," Loumal of Intemational Money and Finance 8, 1989, pp. 5-28.

Baldwin, Richard and Paul Krugman, "Persistent Trade Effects of Large Exchange Rate Shocks," Quarterly Joumal Of Economics, November 1989, pp. 635-654.

Dornbusch, Rudi, "Exchange Rate and Prices," American Economic Review, 1987, pp. 93 106.

Dixit, Avinash, "Hysteresis, Import Penetration, and Exchange-Rate Pass-Through," Quarterly Joumal of Economics, May 1989, pp. 205-228 and Joseph E. Stiglitz, "Monopolistic Competition and Optimum Product Diversity." American Economic Review 67, 1977, pp. 297-308.

Edwards, Sebastian. "Capital Flows, Foreign Direct Investment, and Debt- Equity Swaps in Developing Countries," NBER Working paper no. 3497, October 1989.

Fischer, Stanley. "Wage Indexation and Macroeconomic Stability," Vol. 5, Camegie-Rochester Conferences on Public Policy, Joumal of Monetary Economics, Suppl. 1977, pp 107 47.

Flood, Robert P. and Marion Nancy P., "The Transmission of Disturbances under Alternative Exchange Rate Regimes with Optimal Indexation," Quarterly Joumal Of Economics, February 1982, pp. 43-66.

Frankel, A. Jeffrey and Kenneth Froot , "The Rationality of the Foreign Exchange Rate," American Economic Review, May 1990.

Froot, Kenneth A. and Jeremy C. Stein, "Exchange Rates and Foreign Direct Investment," NBER Working Paper 2914, March 1989.

Goldberg, Linda. "Nominal Exchange Rate Patterns: Correlation with Entry, Exit and Investment in the United State Industry", NBER Working paper 3249 , January 1990. 
Gray, Jo Anna. "Wage Indexation: A Macro-Economic Approach," Lournal of Monetary Economics, April 1976, pp. 221-35.

Helpman Elhanan and Paul Krugman, Trade Policy and Market Structure, the MIT Press, 1989.

Klein, Michael and Eric Rosengren, "Foreign Direct Investment Outflow From The U. S.," manuscript, 1990.

Krugman, Paul, 1989, Exchange-Rate Instability, the MIT Press, Cambridge.

Marston Richard C. and Tumovsky, Stephen J. , "Imported Material Prices, Wage Policy and Macroeconomic Stabilization," Canadian Joumal of Economic, 1985, pp. 273-84.

Svensson Lars E. O, and Sweder van Wijnbergen, "Excess Capacity, Monopolistic Competition and International Transmission of Monetary Disturbances," The Economic Loumal, 1989, pp. 785-805.

Turnovsky, Stephen J., "Wage Indexation and Exchange Market Intervention in a Small Open Economy," Canadian Journal of Economic, 1983, pp. 574-92. 
</ref_section> 